\title{
SEM and EDS study of TotalFill BC Sealer and GuttaFlow Bioseal root canal sealers
}

\section{Badania SEM i EDS uszczelniaczy kanałowych TotalFill BC Sealer i GuttaFlow Bioseal}

\author{
Przemysław Reszka ${ }^{1, A-D, F}$, Alicja Nowicka ${ }^{2, E, F}$, Włodzimierz Dura ${ }^{3, C, E, F}$, Ewa Marek ${ }^{3, C, E, F}$, Mariusz Lipski, ${ }^{3, A, D-F}$ \\ ${ }^{1}$ Private Dental Practice, Koszalin, Poland \\ ${ }^{2}$ Department of Conservative Dentistry and Endodontics, Faculty of Medicine and Dentistry, Pomeranian Medical University of Szczecin, Poland \\ ${ }^{3}$ Department of Preclinical Conservative Dentistry and Preclinical Endodontics, Faculty of Medicine and Dentistry, Pomeranian Medical University of Szczecin, Poland \\ A - research concept and design; $\mathrm{B}$ - collection and/or assembly of data; $\mathrm{C}$ - data analysis and interpretation; \\ $D$ - writing the article; $E$ - critical revision of the article; $F$ - final approval of the article
}

Address for correspondence

Mariusz Lipski

E-mail: lipam@pum.edu.pl

\section{Funding sources}

None declared

Conflict of interest

None declared

Received on January 21, 2019

Reviewed on February 3, 2019

Accepted on March 12, 2019

Published online on May 27, 2019

\section{Cite as}

Reszka P, Nowicka A, Dura W, Marek E, Lipski M.

SEM and EDS study of TotalFill BC Sealer and GuttaFlow Bioseal root canal sealers. Dent Med Probl. 2019;56(2):167-172. doi:10.17219/dmp/105561

DOI

$10.17219 / \mathrm{dmp} / 105561$

Copyright

C 2019 by Wroclaw Medical University

This is an article distributed under the terms of the

Creative Commons Attribution 3.0 Unported License (CC BY 3.0)

(https://creativecommons.org/licenses/by/3.0/)

\section{Abstract}

Background. Recently, a new generation of calcium silicate-based root canal sealers has been developed. These new types of sealers have the ability to set in wet environment, have high alkalinity and present potential antimicrobial activity.

Objectives. The aim of this study was to determine the chemical composition and microstructure of 2 novel calcium silicate-containing root canal sealers - TotalFill ${ }^{\circledR}$ BC Sealer and GuttaFlow ${ }^{\circledR}$ Bioseal.

Material and methods. The tested sealers were prepared according to the manufacturers' instructions. Sixteen cylindrical dishes (inner diameter: $4 \mathrm{~mm}$; height: $3 \mathrm{~mm}$ ) were placed on a glass Petri dish and packed with the materials. The Petri dish was transferred to an incubator. After the sealers set, excess material was removed with diamond discs and polishing paste. The materials were assessed using scanning electron microscopy (SEM) and energy dispersive spectroscopy (EDS) X-ray microanalysis.

Results. Both TotalFill BC Sealer and GuttaFlow Bioseal contained calcium, zirconium, oxygen, carbon, silicon, and a trace of sodium. In the case of TotalFill BC Sealer, trace amounts of copper and technetium were also present, and for GuttaFlow Bioseal, iron, zinc, and a trace of magnesium and hafnium were noted. No bismuth was found. Both of the assessed sealers contained fine particles embedded in the matrix; however, GuttaFlow Bioseal also had larger particles with a diameter of 2-10 $\mu \mathrm{m}$.

Conclusions. TotalFill BC Sealer represents a higher degree of purity in comparison with GuttaFlow Bioseal. The clinical implications of heavy metals present in GuttaFlow Bioseal need to be investigated. Both materials have a fine particle structure, which is desirable for root canal sealers.

Key words: heavy metals, scanning electron microscopy, energy dispersive spectroscopy, calcium silicate-based root canal sealers

Słowa kluczowe: metale ciężkie, skaningowa mikroskopia elektronowa, rentgenowska spektroskopia energodyspersyjna, uszczelniacze kanałowe na bazie krzemianów wapnia 


\section{Introduction}

Root canal obturation is traditionally performed using gutta-percha in conjunction with a root canal sealer. The use of a sealer is necessary to fill the space between the core material and the dentin wall as well as the voids within the core material, and it also serves as a lubricating agent, thus helping to obtain a fluid-tight seal. ${ }^{1,2}$ Without a sealer, canal fillings exhibit greater leakage. ${ }^{3,4}$

Nowadays, various types of root canal sealers are available, including materials based on resin, zinc oxide with eugenol, siloxane, and calcium hydroxide..$^{5}$ Recently, diand tricalcium silicate-based root canal sealers have received significant attention due to their favorable physicochemical properties. ${ }^{6-9}$ These sealers are biocompatible and nontoxic. ${ }^{10-12}$ Another advantage of these materials is their ability to form hydroxyapatite during the setting process as well as their interaction with the dentin (infiltration of the mineral content of bioceramic-based sealer into the intertubular dentin) and forming the so-called mineral infiltration zone. ${ }^{12,13}$

One of the newer calcium silicate-based root canal sealers that has appeared on the European market is TotalFill ${ }^{\circledR}$ BC Sealer (FKG Dentaire, La Chaux-de-Fonds, Switzerland). In Canada, it has been available for several years as iRoot $^{\circledR}$ BC Sealer (Innovative Bioceramix, Inc., Vancouver, Canada), and in the USA as EndoSequence ${ }^{\circledR}$ BC Sealer (Brasseler USA, Savannah, USA). ${ }^{13}$ According to the manufacturer, it is composed of dicalcium silicate, tricalcium silicate, calcium hydroxide, monobasic calcium phosphate, zirconium oxide, tantalum oxide, filler, and thickening agents. TotalFill BC Sealer is premixed and is a ready-to-use calcium-silicate based material. This type of root canal sealer absorbs humidity during setting (dentinal fluid) and sets by itself in the root canal without previous mixing. TotalFill BC Sealer has demonstrated cytocompatibility, ${ }^{14,15}$ bond strength and dentin penetrability. ${ }^{14-16}$

Another new root canal sealer containing calcium silicate is GuttaFlow ${ }^{\circledR}$ Bioseal (Coltène/Whaledent, Altstätten, Switzerland), also known as GuttaFlow 3. This material is composed of gutta-percha, polydimethylsiloxane, zirconium oxide, platinum, and bioactive ceramic glass. GuttaFlow Bioseal was developed to improve GuttaFlow (Coltène/Whaledent) bioactivity, promoting the regeneration of the periapical tissues. It shows good physicochemical properties. ${ }^{16-18}$

In the researchers' previous study, the chemical composition of MTA-FILLAPEX available on the market for many years and 2 novel calcium silicate-based root canal sealers (BioRoot ${ }^{\mathrm{TM}}$ RSC and Well-Root ${ }^{\mathrm{TM}} \mathrm{ST}$ ) were evaluated. ${ }^{19}$ The aim of the present study was to determine the chemical elements in 2 other new calcium silicate-containing root canal sealers: TotalFill BC Sealer and GuttaFlow Bioseal. As in the previous study, the assessment took account of the content of heavy metals.

\section{Material and methods}

Two root canal sealers, TotalFill BC Sealer and GuttaFlow Bioseal, were used as the experimental materials. GuttaFlow Bioseal was prepared in accordance with the manufacturer's instructions; TotalFill BC Sealer was not mixed, as it is a premixed root canal sealer, designed to set in a humid environment. Sixteen cylindrical dishes with an inner diameter of $4 \mathrm{~mm}$ and a height of $3 \mathrm{~mm}$ were placed on a glass Petri dish and filled with the materials. The Petri dish was covered with damp gauze and transported to a laboratory thermostat $\left(37^{\circ} \mathrm{C} ; 95 \%\right.$ relative humidity). After the sealers set, excess material was trimmed to the surface level of the dishes using diamond discs and polishing paste, and characterized with scanning electron microscopy (SEM) (FE-SEM SU-70; Hitachi, Ltd., Tokyo, Japan) and energy dispersive spectroscopy (EDS) X-ray microanalysis using NORAN ${ }^{\mathrm{TM}}$ System 7 UltraDry X-ray Detector (Thermo Fisher Scientific, Grand Island, USA). The samples were coated with the goldpalladium alloy for electrical conductivity. The metals used to sputter coat the specimens were excluded from the percentage found.

\section{Statistical analysis}

The data was evaluated for normality using the Shapiro-Wilk test. As the data did not follow normal distribution, the Mann-Whitney $U$ test was used. The level of significance was set at $p=0.05$.

\section{Results}

The backscatter scanning electron micrographs at $\times 1000$ and EDS profiles for the selected areas of identical sizes of the tested materials $\left(\sim 0.01 \mathrm{~mm}^{2}\right)$ are shown in Fig. 1 and 2. The collected EDS data is given in Table 1. The EDS microanalysis of the root canal sealers revealed high content of calcium, silicon, oxygen, zirconium, carbon, and a trace of sodium. Statistical analysis showed more calcium and oxygen in TotalFill BC Sealer than in GuttaFlow Bioseal $(p<0.0002)$, whereas GuttaFlow Bioseal contained more silicon, carbon and zirconium than TotalFill BC Sealer $(p<0.0002)$. In the case of TotalFill BC Sealer, trace amounts of copper and technetium were also present, and for GuttaFlow Bioseal, iron, zinc, and a trace of magnesium and hafnium were noted.

TotalFill BC Sealer showed relatively homogenous aggregates of very small, round particles embedded in the matrix. The EDS analysis showed that these particles were mainly composed of calcium, silicon, carbon, oxygen, and zirconium; the cementation phase was composed of calcium, silicon, oxygen, and carbon (Fig. 3). 

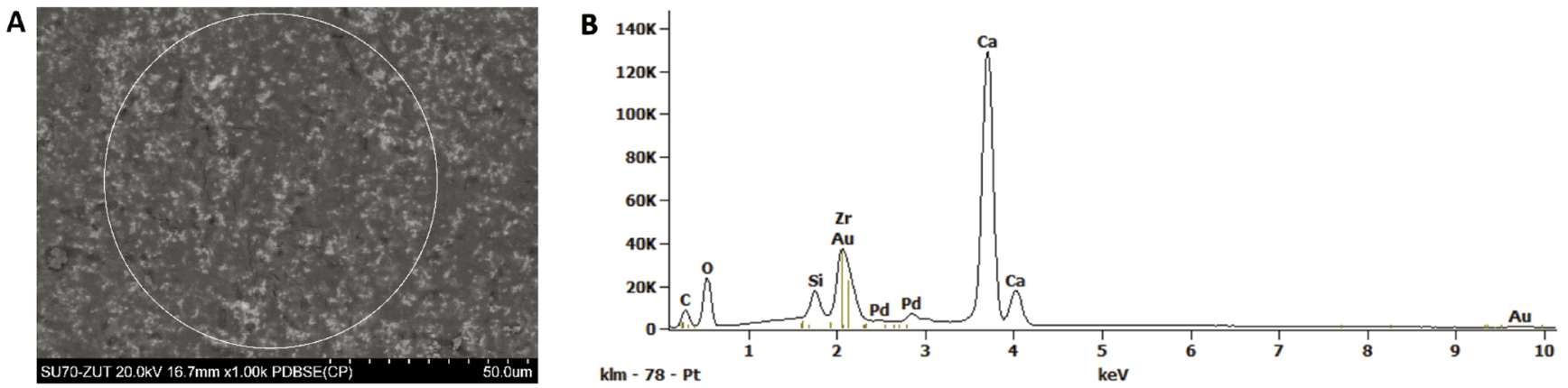

Fig. 1. TotalFill BC Sealer: backscatter scanning electron micrographs at $\times 1000$ magnification (A); EDS X-ray microanalysis (B) EDS - energy dispersive spectroscopy.
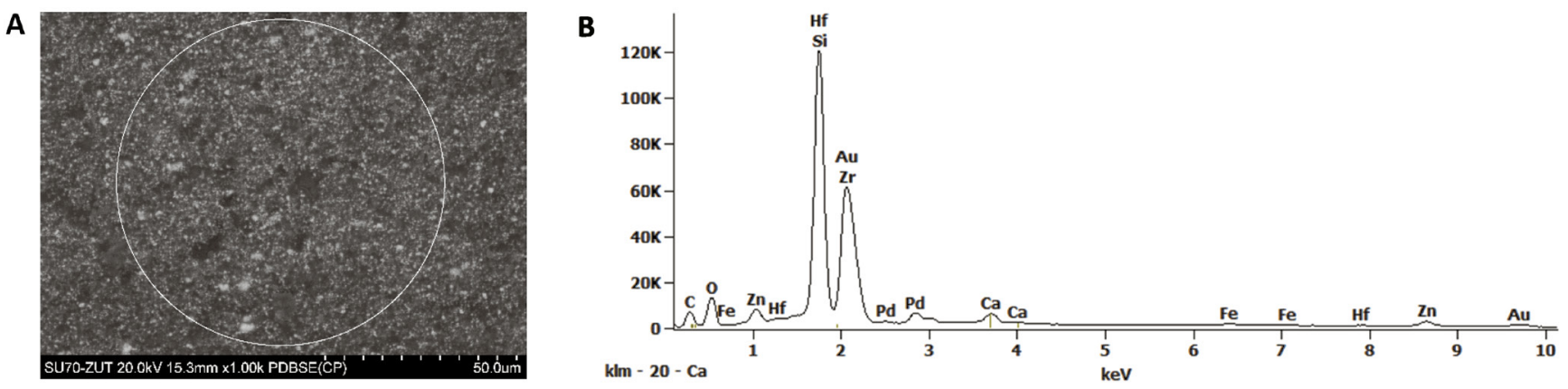

Fig. 2. GuttaFlow Bioseal: backscatter scanning electron micrographs at $\times 1000$ magnification (A); EDS X-ray microanalysis (B)

A

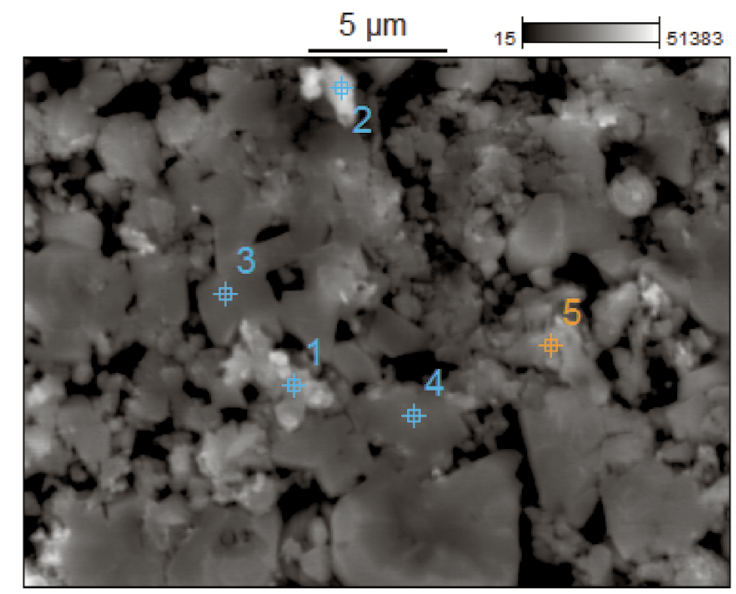

B2

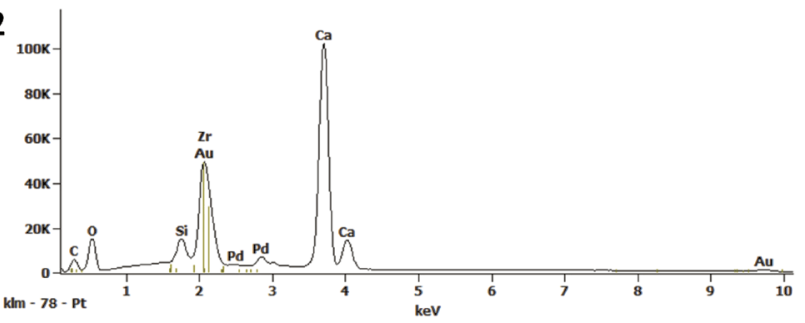

B4

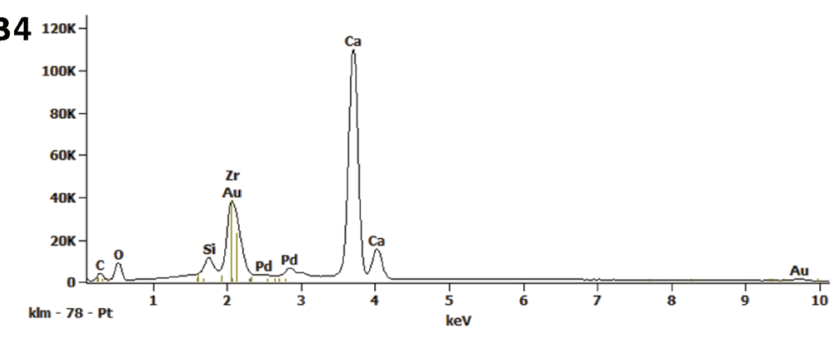

B1

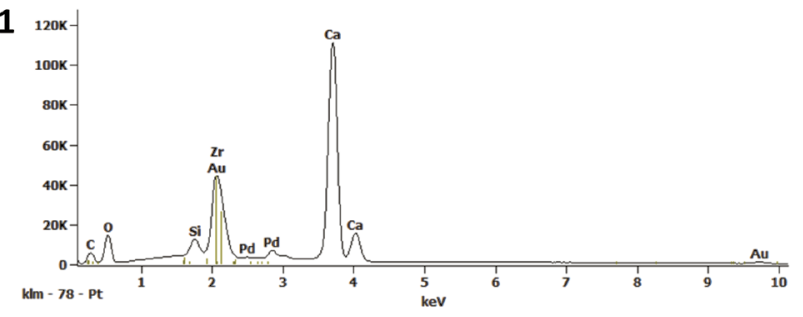

B3

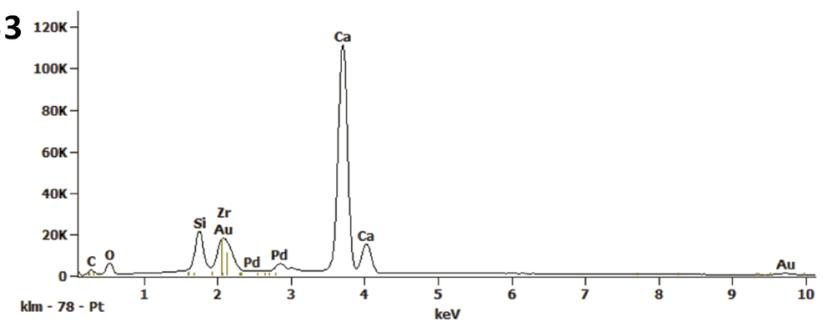

B5

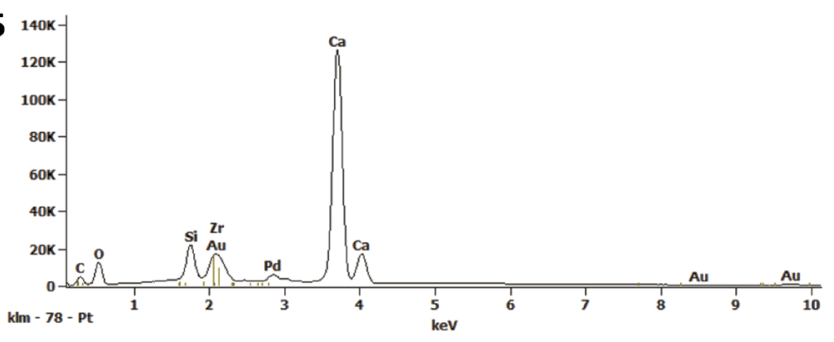

Fig. 3. TotalFill BC Sealer: backscatter scanning electron micrographs at $\times 2500$ magnification (A); EDS X-ray microanalysis of particles and cementation phase (B1-B5) 
GuttaFlow Bioseal showed multiple aggregates of nanoparticles. The EDS analysis showed that these very small, round particles were mainly composed of silicon, calcium, zirconium, and oxygen. Among these nanoparticles, larger roundish particles were present. The particles with a diameter of about 5-10 $\mu \mathrm{m}$ contained calcium, silicon and phosphorus; the smaller particles (approx. 2-3 $\mu \mathrm{m}$ ) were rich in calcium, silicon, zirconium, and oxygen. The point analysis also showed aluminum (Fig. 4).

Neither TotalFill BC Sealer nor GuttaFlow Bioseal contained bismuth.

\section{Discussion}

The present study tested 2 calcium silicate-based root canal sealers recently introduced on the market. As predicted, EDS showed the presence of calcium, silicon and

A

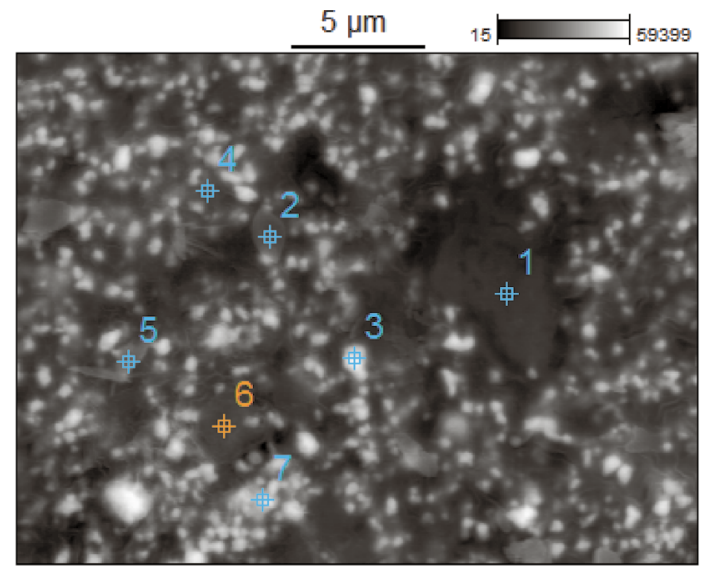

B2

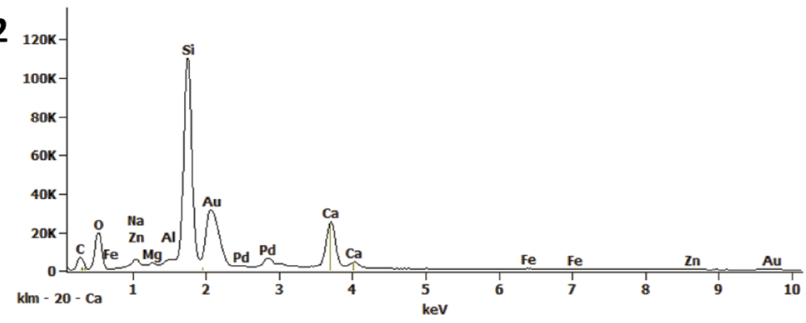

B4

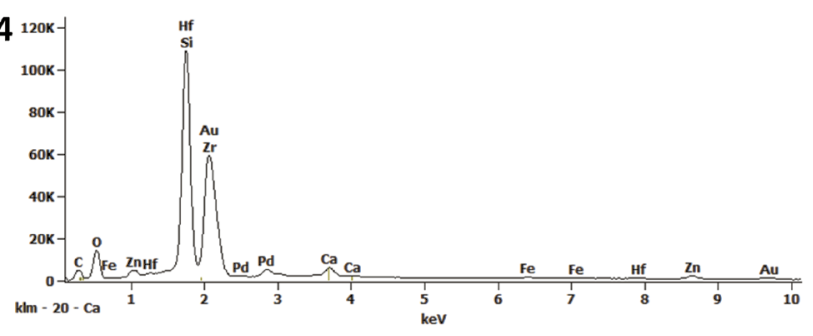

B6

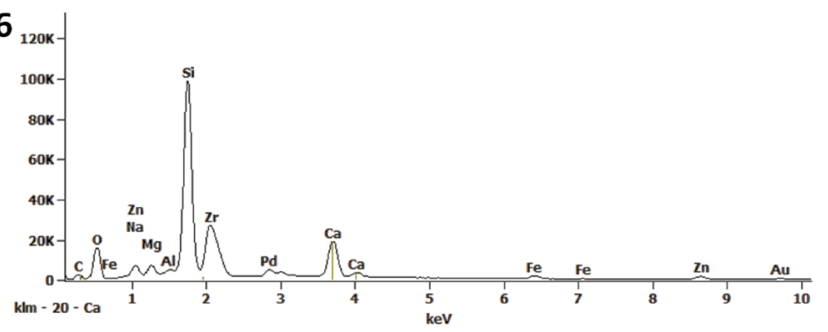

Table 1. Percentage (wt\%) of elements in the tested root canal sealers

\begin{tabular}{l|c|c|}
\multirow{2}{*}{ Element } & \multicolumn{2}{|c}{ Root canal sealer } \\
\cline { 2 - 3 } $\mathrm{C}$ & TotalFill BC Sealer & GuttaFlow Bioseal \\
$\mathrm{O}$ & $4.21 \pm 0.51$ & $9.16 \pm 0.74$ \\
$\mathrm{Na}$ & $40.7 \pm 3.31$ & $21.41 \pm 1.811$ \\
$\mathrm{Mg}$ & trace & trace \\
$\mathrm{Si}$ & - & trace \\
$\mathrm{Ca}$ & $1.67 \pm 0.88$ & $26.89 \pm 3.52$ \\
$\mathrm{Fe}$ & $45.1 \pm 3.72$ & $2.09 \pm 0.74$ \\
$\mathrm{Zn}$ & - & $1.02 \pm 0.31$ \\
$\mathrm{Zr}$ & - & $4.31 \pm 1.0$ \\
$\mathrm{Hf}$ & $7.3 \pm 0.72$ & $32.26 \pm 4.73$ \\
$\mathrm{Cu}$ & - & trace \\
$\mathrm{TC}$ & trace & - \\
\hline
\end{tabular}

Data is presented as mean \pm standard deviation (SD).
B1

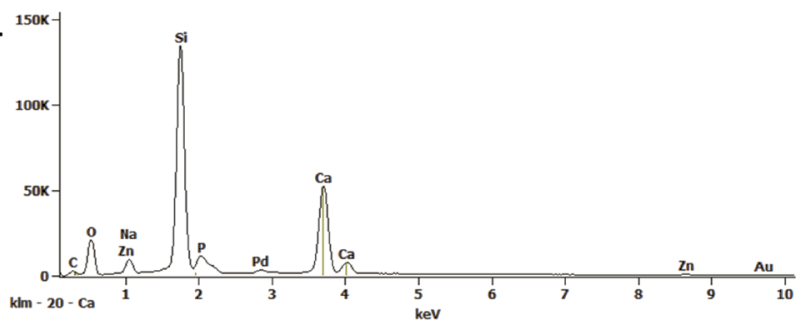

B3

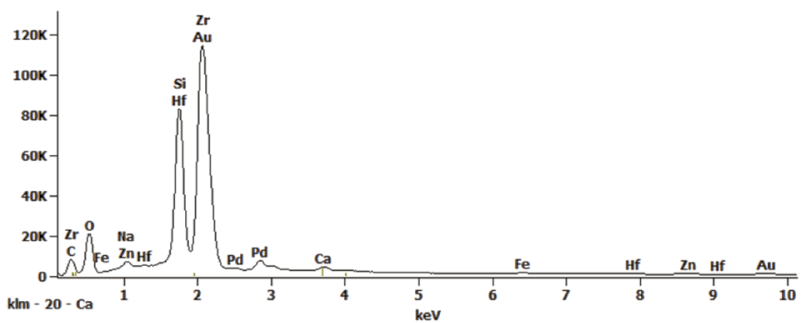

B5

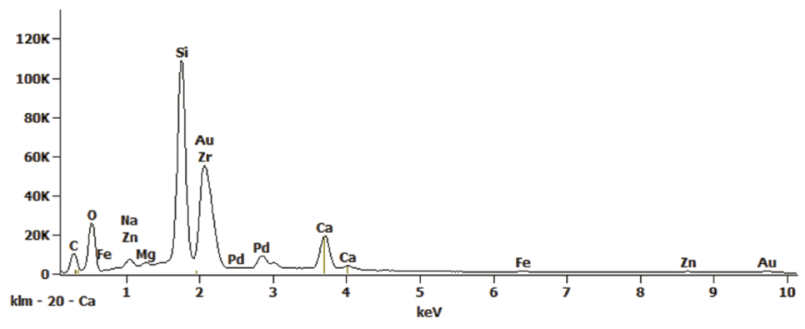

B7

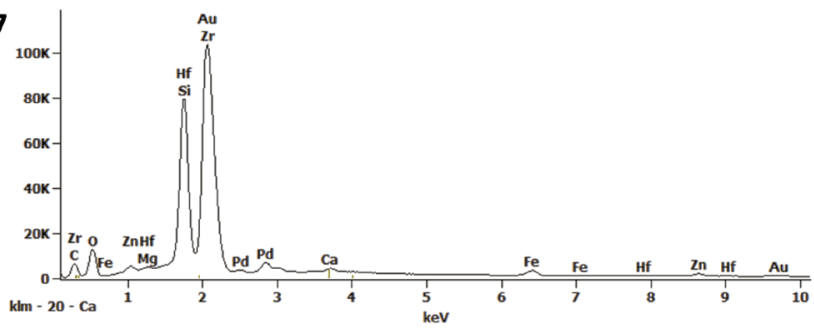

Fig. 4. GuttaFlow Bioseal: backscatter scanning electron micrographs at ×2500 magnification (A); EDS X-ray microanalysis of particles and cementation phase (B1-B7) 
oxygen in the composition of both TotalFill BC Sealer and GuttaFlow Bioseal. This observation suggests that these sealers would probably favor bioactivity and would be expected to interact with the dentin. Such bioactivity has been demonstrated by other root canal sealers containing calcium silicates in a similar amount. ${ }^{6,20,21}$

The analysis of the chemical composition of TotalFill BC Sealer also showed the presence of traces of copper and technetium. Although they can adversely affect human health, the very small amount of them in the tested sealer is clinically insignificant. ${ }^{21,22}$ In GuttaFlow Bioseal, zinc, magnesium, iron, and aluminum were also found. While the relatively small amount of magnesium and aluminum does not raise concerns, the relatively high content of iron $(1.02 \mathrm{wt} \%)$ and zinc $(4.31 \mathrm{wt} \%)$ requires testing the toxicity of these heavy metals.

Several reports have shown that calcium silicate-based root canal sealers have an unfavorable effect on tooth color, which is of clinical relevance in anterior teeth. ${ }^{13,23}$ Causal are heavy metal compounds such as bismuth oxide, used as a radiopacifier. ${ }^{23}$ However, increasing the concentration of bismuth oxide to increase radiopacity has no significant effect on the level of discoloration. ${ }^{24}$ The present study showed that neither TotalFill BC Sealer nor GuttaFlow Bioseal contained bismuth. However, GuttaFlow Bioseal contains iron (1.02 wt\%), which has the potential of staining the tooth. For this very reason, the chemical composition of conventional mineral trioxide aggregate (gray MTA) was changed many years ago (iron was eliminated) and an improved formulation was later introduced as white MTA. ${ }^{13,25}$

The EDS analysis showed that both TotalFill BC Sealer and GuttaFlow Bioseal are rich in zirconium and oxygen. Zirconium oxide is an alternative radiopacifier, which has been recently manufactured and used to limit the content of heavy metals and substitute bismuth oxide in calcium silicate-based materials. Zirconium oxide has become popular due to adequate radiopacity and lack of interference with the hydration of calcium silicate-based materials. This oxide, in comparison with bismuth oxide, is more biocompatible and does not cause tooth discoloration. ${ }^{22,25}$

The SEM analysis confirmed that both TotalFill BC and GuttaFlow Bioseal consisted of very small particles, although in the case of GuttaFlow Bioseal, particles of a diameter of approx. $10 \mu \mathrm{m}$ were also observed. In an earlier study on other calcium silicate-based root canal sealers, the size of the particles was also evaluated. ${ }^{19}$ BioRoot RCS was composed of particles of a diameter of $5-30 \mu \mathrm{m}$ and MTA-FILLAPEX was rich in elongated particles - approx. 10-15 $\mu \mathrm{m}$ in length - and roundish particles - approx. $2-3 \mu \mathrm{m}$ in diameter. ${ }^{19}$ In the research by Hoikkala et al., the SEM examination of GuttaFlow Bioseal revealed bioactive glass-ceramic particles with pointed edges, embedded in a polydimethylsiloxane matrix. The particle size of this ceramic varied in the range of $20-40 \mu \mathrm{m} .{ }^{26}$ Some authors suggest that the particle size is important, because it determines many properties of the material. ${ }^{23,25}$ Smaller particles may better penetrate dentinal tubules, which is confirmed by the research by Akcay et al. ${ }^{27}$ The authors tested dentinal tubule penetration of 4 different sealers: iRoot ${ }^{\mathrm{TM}}$ SP (nowadays TotalFill BC Sealer), GuttaFlow Bioseal, AH Plus ${ }^{\text {TM }}$, and MTA-FILLAPEX. The iRoot SP sealer exhibited a significantly higher dentinal tubule penetration than other sealers, which can be attributed to its very small particle diameter $(<2 \mu \mathrm{m})$. Small particles also hydrate faster than larger particles due to their higher surface-to-volume ratio and provide a low film thickness of the root canal sealer, which is suitable for this dental material and may improve the clinical performance of root canal filling. ${ }^{24,28}$

\section{Conclusions}

TotalFill BC Sealer represents a higher degree of purity in comparison with GuttaFlow Bioseal. The clinical implications of metals contained in GuttaFlow Bioseal need to be investigated. Both materials have a fine particle structure that is desirable for root canal sealers.

\section{ORCID iDs}

Przemysław Reszka (D) https://orcid.org/0000-0001-8545-405X Alicja Nowicka (i) https://orcid.org/0000-0002-0455-4209 Włodzimierz Dura (D) https://orcid.org/0000-0003-0878-528X Ewa Marek (1) https://orcid.org/0000-0002-5299-3185 Mariusz Lipski (iD https://orcid.org/0000-0002-2567-3362

\section{References}

1. Tomson RM, Polycarpou N, Tomson PL. Contemporary obturation of the root canal system. Br Dent J. 2014;216(6):315-322.

2. Duarte MAH, Marciano MA, Vivan RR, Tanomaru Filho M, Tanomaru JMG, Camilleri J. Tricalcium silicate-based cements: Properties and modifications. Braz Oral Res. 2018;32(Suppl 1):e70.

3. Evans JT, Simon JH. Evaluation of the apical seal produced by injected thermoplasticized gutta-percha in the absence of smear layer and root canal sealer. J Endod. 1986;12(2):101-107.

4. Hata I, Kawazoe S, Toda T, Weine F. Sealing ability of Thermafil with or without sealer. J Endod. 1992;18(7):322-336.

5. Ørstavik D. Materials used for root canal obturation: Technical, biological and clinical testing. Endod Topics. 2005;12(1):25-38.

6. Urban K, Neuhaus J, Donnermeyer D, Schäfer E, Dammaschke T. Solubility and $\mathrm{pH}$ value of 3 different root canal sealers: A longterm investigation. J Endod. 2018;44(11):1736-1740.

7. Prüllage RK, Urban K, Schäfer E, Dammaschke T. Material properties of a tricalcium silicate-containing, a mineral trioxide aggregatecontaining, and an epoxy resin-based root canal sealer. J Endod. 2016;42(12):1784-1788

8. Donnermeyer D, Dornseifer P, Schäfer E, Dammaschke T. The pushout bond strength of calcium silicate-based endodontic sealers. Head Face Med. 2018;14(1):13.

9. Donnermeyer D, Vahdat-Pajouh N, Schäfer E, Dammaschke T. Influence of the final irrigation solution on the push-out bond strength of calcium silicate-based, epoxy resin-based and silicone-based endodontic sealers. Odontology. Epub 2018. doi:10.1007/s10266-018-0392-z

10. Jung S, Libricht V, Sielker S, Hanisch MR, Schäfer E, Dammaschke T. Evaluation of the biocompatibility of root canal sealers on human periodontal ligament cells ex vivo. Odontology. 2019;107(1):54-63.

11. Jung S, Sielker S, Hanisch MR, Libricht V, Schäfer E, Dammaschke T. Cytotoxic effects of four different root canal sealers on human osteoblasts. PLoS One. 2018;13(3):e0194467. 
12. Kebudi Benezra M, Schembri Wismayer P, Camilleri J. Interfacial characteristics and cytocompatibility of hydraulic sealer cements. J Endod. 2018;44(6):1007-1017.

13. Donnermeyer D, Bürklein S, Dammaschke T, Schäfer E. Endodontic sealers based on calcium silicates: A systematic review. Odontology. Epub 2018. doi:10.1007/s10266-018-0400-3

14. Carvalho NK, Prado MC, Senna PM, et al. Do smear-layer removal agents affect the push-out bond strength of calcium-silicate based endodontic sealers? Int Endod J. 2017;50(6):612-619.

15. Gokturk H, Bayram E, Bayram HM, Aslan T, Ustun Y. Effect of double antibiotic and calcium hydroxide pastes on dislodgement resistance of an epoxy resin-based and two calcium silicate-based root canal sealers. Clin Oral Investig. 2017;21(4):1277-1282.

16. Agrafioti A, Koursoumis AD, Kontakiotis EG. Re-establishing apical patency after obturation with gutta-percha and two novel calcium silicate-based sealers. Eur J Dent. 2015;9(4):457-461.

17. Gandolfi MG, Siboni F, Prati C. Properties of a novel polysiloxaneguttapercha calcium silicate-bioglass-containing root canal sealer. Dent Mater. 2016;32(5):e113-e126.

18. Reszka P, Kucharski $Ł$, Klimowicz A, Lipski M. Alkalizing properties of selected calcium-silicate root canal sealers. An in vitro study [in Polish]. Pomeranian J Life Sci. 2018;64(4):36-41.

19. Reszka P, Nowicka A, Lipski M, Dura W, Droździk A, Woźniak K. A comparative chemical study of calcium silicate containing and epoxy resin-based root canal sealers. Biomed Res Int. 2016;2016:9808432.

20. Siboni F, Taddei P, Zamparini F, Prati C, Gandolfi MG. Properties of BioRoot RCS, a tricalcium silicate endodontic sealer modified with povidone and polycarboxylate. Int Endod J. 2017;50(Suppl 2):e120-e136.

21. Gaetke LM, Chow-Johnson HS, Chow CK. Copper: Toxicological relevance and mechanisms. Arch Toxicol. 2014;88(11):1929-1938.

22. Touchefeu Y, Franken P, Harrington KJ. Radiovirotherapy: Principles and prospects in oncology. Curr Pharm Des. 2012;18(22):3313-3320.

23. Możyńska J, Metlerski M, Lipski M, Nowicka A. Tooth discoloration induced by different calcium silicate-based cements: A systematic review of in vitro studies. J Endod. 2017;43(10):1593-1601.

24. Torabinejad M, Parirokh $\mathrm{M}$, Dummer PMH. Mineral trioxide aggregate and other bioactive endodontic cements: An updated overview - part II: Other clinical applications and complications. Int Endod J. 2018;51(3):284-317.

25. Walsh RM, He J, Schweitzer J, Opperman LA, Woodmansey KF. Bioactive endodontic materials for everyday use: A review. Gen Dent. 2018;66(3):48-51.

26. Hoikkala NPJ, Wang X, Hupa L, Smått JH, Peltonen J, Vallittu PK. Dissolution and mineralization characterization of bioactive glass ceramic containing endodontic sealer Guttaflow Bioseal. Dent Mat J. 2018;37(6):988-994.

27. Akcay M, Arslan H, Durmus N, Mese M, Capar ID. Dentinal tubule penetration of AH Plus, iRoot SP, MTA fillapex, and guttaflow bioseal root canal sealers after different final irrigation procedures: A confocal microscopic study. Lasers Surg Med. 2016;48(1):70-76.

28. Komabayashi T, Spångberg LS. Comparative analysis of the particle size and shape of commercially available mineral trioxide aggregates and Portland cement: A study with a flow particle image analyzer. J Endod. 2008;34(1):94-98. 